\title{
An Emotion-based Model for Improving Students’ Engagement Using Agent-based Social Simulator
}

\author{
Latha Subramainan $^{\# 1}$, Moamin A Mahmoud ${ }^{\# 2}$, Mohd Sharifuddin Ahmad ${ }^{\# 3}$, Mohd Zaliman Mohd Yusoff*

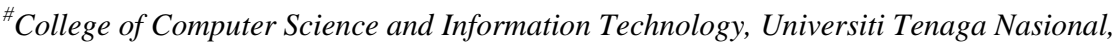 \\ Jalan IKRAM-UNITEN, 43000 Kajang, Selangor, Malaysia \\ latha0522@gmail.com ${ }^{1},\left\{\right.$ moamin $^{2}$, sharif $\left.^{3}\right\} @$ uniten.edu.my
}

*Business Development Unit, TNB Integrated Learning Solution Sdn Bhd - ILSAS

Selangor, Malaysia

zaliman.yusoff@tnb.com.my

\begin{abstract}
Students' emotional engagement in classrooms has always been regarded as a crucial factor influencing educational outcomes. Emotionally engaged students are highly motivated to attend classes and participate actively in discussions. Conversely, emotionally disengaged students are habitual truants and/or often misbehave in classrooms. It is time-consuming to conduct research using traditional methods such as data collection or questionnaire. Furthermore, as these experiments are conducted on humans, limited settings can be organized and difficult to control/monitor. Therefore, in this paper, we present our work-in-progress to address the problem. We propose a conceptual emotion-based model that is animated by an agent-based social simulator. We also propose an algorithmic approach that decides whether to maintain or update a proposed action plan for improving students' engagement in a classroom. The rudimentary theory of this proposal is based on three main elements: the engagement level of students, the emotional state of a lecturer and the emotional state of students in a classroom.
\end{abstract}

Keywords - student engagement; emotions; agent-based social simulation; emotional states; E-BDI

\section{INTRODUCTION}

Students' emotional engagement in classrooms is a longstanding issue and regarded as a crucial factor that influences several educational outcomes. Emotionally engaged students are highly motivated to attend classes, and actively participate in discussions and assessments [1]. On the other hand, emotionally disengaged students are usually habitual truants and/or occasionally misbehave in classrooms [1]. Such students ultimately end up getting poor academic results, involving in many disciplinary actions and occasionally dropping out of colleges.

Several researches have been conducted to study the problem of poor engagement in classrooms using traditional methods such as data collection using questionnaire, and setting up experiments [2]-[5]. But, using traditional methods to conduct experiments consume considerable time and effort. Furthermore, since these experiments are applied to a human society, there are very limited settings to be tested and the cost would be excessive if multiple settings are applied [6]. Studies have indicated that it is challenging to manage and control a human society to conduct multiple experiments or repeat experiments with the same settings [7].
Thus, traditional methods have a poor success rate in mitigating the problem [6].

Social studies have identified three dimensions of student engagement, which are Behavioral, Emotional, and Cognitive engagement [8]. Ample research have been conducted on Behavioral and Cognitive engagement while Emotional engagement received little attention [9]. This is attested by [9] who surmises that research on emotion have mostly been neglected as a factor to improve student engagement although researchers from social studies emphasize the importance of emotion on students' engagement.

To address this issue, we propose a conceptual emotionbased model using agent-based social simulation. The preliminary theory of this proposal is based on three main elements in a classroom; the engagement level of students, the emotional state of a lecturer and the emotional state of students.

The remainder of this paper is generally organized as follows: Section II introduces the related works of student engagement that highlight the importance of emotion and agent-based social simulation. Section III shows the proposed emotion-based model on how it is implemented. 
Section IV presents the lecturer agent architecture. Section V discusses the preliminary process for students' engagement level, lecturer' emotional state and students' emotional state. In Section VI, a conclusion is drawn and future work is described.

\section{MATERIALS AND METHOD}

\section{A. Related Works on Student Engagement}

Students' engagement issue has enjoyed widespread attention in the literature since the mid-1980s. Its beginning can be traced back three decades ago via Alexander Astin's work on student involvement in 1984 [10]. Primarily, students' engagement has been focused on improving achievement, positive behaviors, and a sense of belonging in students so that they remain in school. Progressively, students' engagement strategies are further developed and broadly applied as a way to manage classroom behaviors. According to [11], engagement is more important than involvement or participation as it requires feelings and sense making as well as activity.

A few research examines the role of emotions in classrooms interactions. For example, in [2], they consider achieving goals and emotions as one of the most significant contextual factors shaping students' engagement. Proponent to this idea, our study explores emotional engagement as a factor to strengthen students' engagement [2].

Emotions are an integral part of education and play a pivotal role in a classroom. Continuous exploration on emotion research in education reveals the importance of emotional states for both lecturers and students [12]. Researchers believe that emotions have a profound impact on students' motivation, learning, and performance [13]. There are a number of popular educational psychologists such as Pekrun, Goetz and Frenzel who examined a broader range of emotions in the education domain and focused on obtaining emotional responses of students in an academic setting [9]. They developed an Achievement Emotions Questionnaire (AEQ), to identify emotions of students during class, while studying and during examinations. They focused on the role of control and value appraisals in shaping achievement emotions related to students' engagement and performance.

In [14], the authors investigated the emotions of students (e.g. enjoyment, pride, anxiety, anger and boredom) while they complete their homework. Their study examines the differences between homework emotions and classroom emotions. Both emotions are evaluated separately using four different subject domains such as Mathematics, Physics, German, and English. They reported that both homework emotions and classroom emotions have clear connections with students' academic self-concept and achievement outcomes within the domains.

Reference [15] proposed a circumflex model of affect to study how four affective states namely activated positive, activated negative, deactivated positive, deactivated negative are associated with school students' social-behavioral engagement during small group learning. Their research highlighted the importance of the way emotions shape students' engagement during small group instructions.

Intelligent software agents have been widely used in distributed artificial intelligence due to their autonomous, self-interested, rational abilities [16]-[22], and social abilities [23]-[27]. An agent is a computer system that is capable of independent (autonomous) action on behalf of its user or owner. Figuring out what needs to be done to satisfy design objectives, rather than constantly being told.

An agent-based social simulation is a method to model systems that comprise of individual, autonomous, cooperating agents [28]. This method can be used to model human behaviors and their effects to others [29]-[31]. This method has enjoyed widespread use in emergency evacuations, transportations, and traffic, car-pooling and disaster response.

One way of characterizing the research area of AgentBased Social Simulation (ABSS) is that it constitutes the intersection of three scientific fields, namely, agent-based computing, the social sciences, and computer simulation [32]. Fig. 1 depicts the three scientific field of ABSS.

Research have proven that ABSS is a powerful tool for modelling and understanding phenomena in various areas such as economics and trading, health care, urban planning and social sciences [33]. However, according to recent research, even though autonomous agents have been popular for decades, they are still in the early phase of implementations [34]. This study falls under the social science category as we plan to model the emotional reaction of real human society via a simulation.

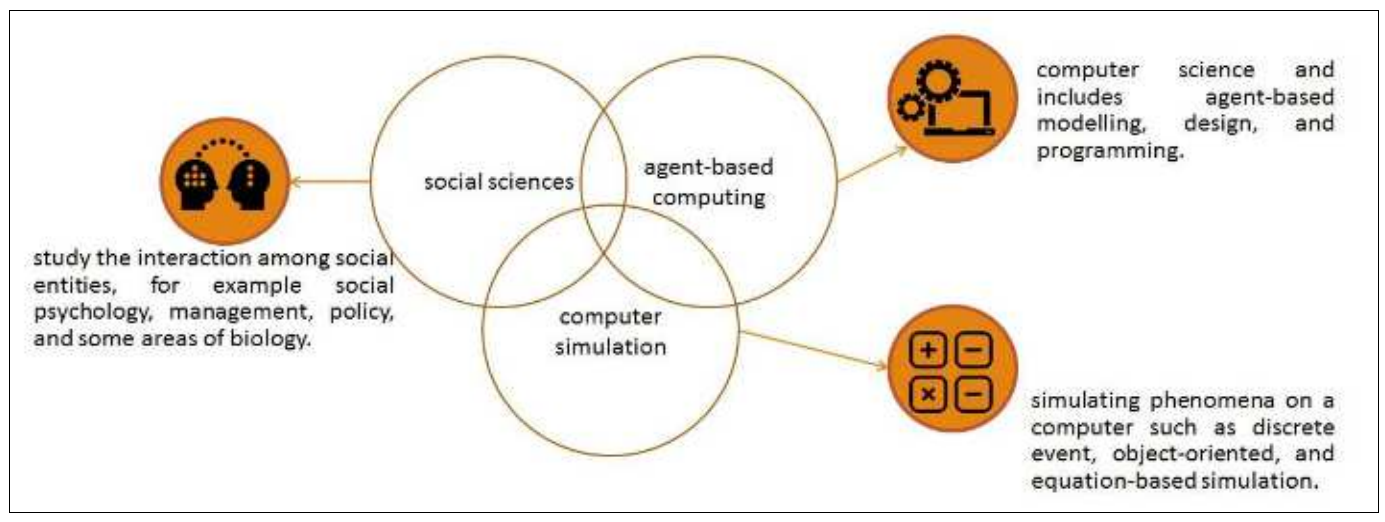

Fig. 1 Three scientific fields of ABSS 


\section{B. The Proposed Emotion-Based Model}

For humans, the process of evaluating students' engagement is simple and straightforward. It can be done through monitoring students' misbehavior and participations. However, to improve the intensity of engagement is very challenging. While different lecturers have different teaching plans, but how effective are these plans? Which plan is more efficient? Is the effectiveness of a particular plan depends on situations? Are there different situations and suitable plans for each situation or group of situations? Many questions have not been clearly answered by the literature due to the difficulty of conducting experiments on humans. Therefore, in this section, we propose an emotion-based model that constitutes software agents to assume the roles of students in a classroom environment seeking answers to the above questions. To do so, agents should be provided with mechanisms to monitor and measure an engagement. The rudimentary theory of this model is based on three main elements in a classroom; the engagement level of students, the emotional state of a lecturer and the emotional states of students.

Lecturer's emotions are as important as students' emotions. From our analysis, we found that students' misbehaviour, motivation and participation factors infer the engagement level in a classroom and influence the lecturers' emotions. In order to evaluate the student's emotion, we need to identify the values of the factors (eg. Misbehaviour, Motivation, and Participation) that have been influencing the lecturers' emotions. In the following section, we use three main Boolean values to determine the scale of the outcomes for each factor as follows:

- When the current emotional state of a lecturer is affected positively, the value is 1 .

- If the lecturer maintains current emotional state, the value is 0 .

- When the current emotional state of the lecturer is affected negatively, the value is -1 .

The process starts with measuring the engagement level of students by the lecturer via three variables: students' misbehaviors, motivation, and participation.

1) Misbehavior (MisB): A student's misbehavior is considered as one of the general factors influencing lecturers' emotions in a classroom. Results have shown that the most disruptive problem behavior is talking out of turn, followed by non-attentiveness, playing video games, daydreaming, and idleness. We determine the evaluation scale for this factor as 0 when the students are not misbehaving and -1 when the students are misbehaving. There is no good behavior.

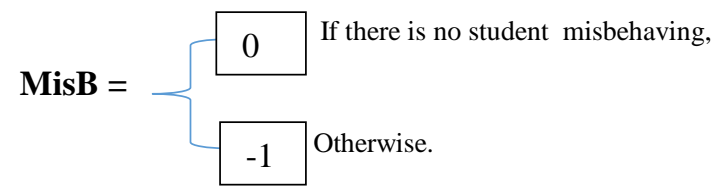

2) Motivation (Mtv): Achievers and highly-motivated students influence lecturers' satisfaction. Usually, highly- motivated students have good class attendance and attentive in class. They maintain eye contact with their lecturer and remain attentive throughout the lesson. However, lecturers need to vary their teaching styles to keep the students motivated to learn and avoid boredom. We determine the evaluation scale for this factor as 1 when the students are motivated and -1 when the students are not motivated.

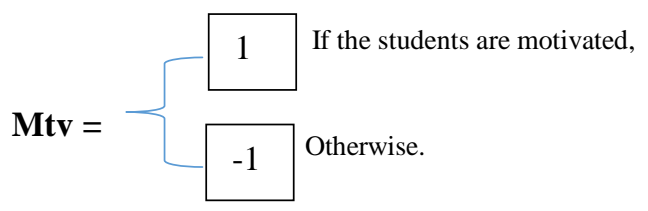

3) Participation ( $P(p)$ : Lecturers prefer to work with students who enhance their academic performance through efforts and participation in class. Students can participate in class by asking questions to their lecturer, taking part in discussions and assessments. We determine the evaluation scale for this factor is 1 when the students are participating and -1 when the students are not participating in a classroom.

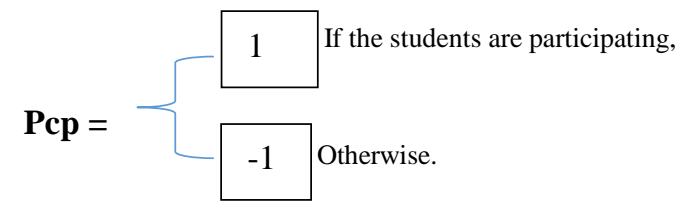

The result of engagement measurement positively or negatively influences a lecturer's emotion. If negatively, the lecturer deploys an action plan that triggers positive students' emotions of which would eventually improve engagement. In contrast, the positively affected teacher is expected to engage an action that would maintain the positive aura to his students. This engagement assessment cycle should continue to maintain the positivity throughout students learning session. Fig. 2 below illustrates the proposed emotion-based model.

As shown in Fig. 2, the Lecturer (Agent) first (1) observes the Students' (Agents) engagement (2) utilizing the misbehaviour, motivation and participation factors for (3) measuring the engagement level. The level of engagement (4) influences the Lecturer's emotional state either positively or negatively. Negative emotion (5) triggers the Lecturer to propose an action plan which subsequently (6) influences the Students' emotional states that would improve their engagement in the classroom (7). The process continues until more than $80 \%$ (will be accurately determined later) of the students display positive factors of misbehaviour, motivation, and participation.

\section{Students' Engagement Measurement}

Based on the literature, we found behavioural issues, motivation and participation are the potential factors to infer students' engagement level. By determining an evaluation scale for these factors, we can measure the engagement level in a classroom. 


\section{Lecturers' Emotion States}

Lecturers experience a wide range of positive and negative emotions in a classroom. They mainly experience six types of emotions, which are, enjoyment and pride as positive emotions; anger, anxiety, boredom and shame as negative emotions [35], [36]. These types are influenced by the engagement factors such as students' misbehaviors [37], motivation [38], and participation [39].

\section{E. Students' Emotion States}

Correspondingly, students also experience six types of emotions, which are, enjoyment and pride as a positive emotion, anger, helplessness, anxiety, and boredom as negative emotions [38]. These types of emotions are influenced by a lecturer's disposition [40] such as poor teaching, uncaring and poor communication skills.

\section{F. Action Plan}

Low engagement level negatively influences the emotional state of a lecturer. Hence, the lecturer needs to initiate an action plan to improve students' engagement level. Consequently, the action plan initiated by the lecturer positively or negatively influences the emotional states of students. Based on this research synthesis, students' engagement could be improved by stimulating discussion, exploration and discovery [26]. Furthermore, the lecturer could stimulate question-answer sessions and a range of interactive activities including providing feedbacks to engage students and their commitment to the class activities [41].

\section{G. Lecturer Agent Architecture}

For an agent to be able to play a lecturer's role, we introduce an Emotion-Belief, Desire, Intention (E-BDI) architecture. The Emotional component represents the emotions being experienced by the lecturer towards students' engagement in a classroom. These emotions trigger the Lecturer's Belief about the engagement level that is either high or low. The Belief component is associated with the Desire component which has precompiled action plans to improve student engagement in a classroom. Both Belief and Desire components aim to achieve an acceptable engagement level and successful action plan determined by the Intentional component. Fig. 3 depicts the Lecturer Agent architecture.

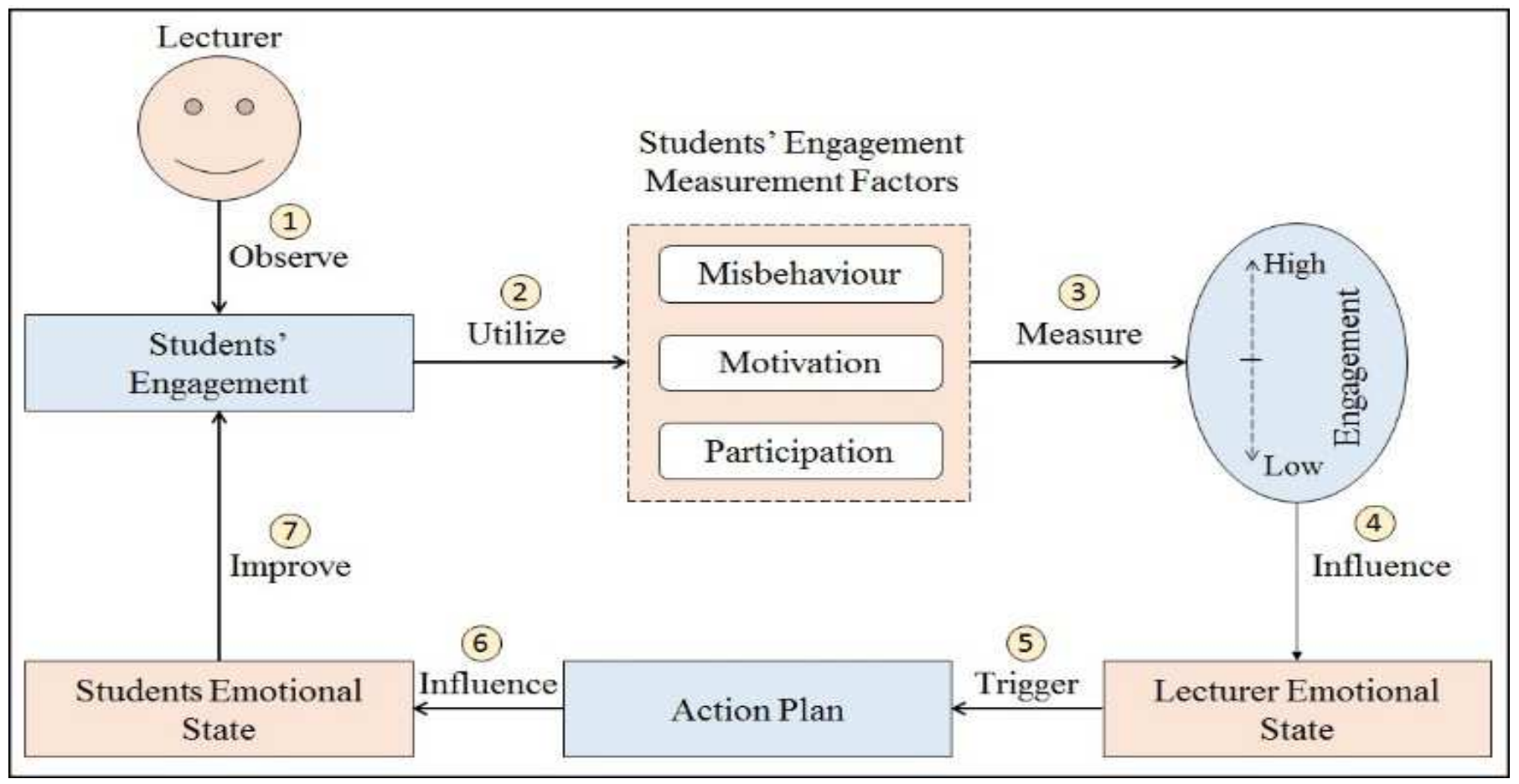

Fig. 2 The proposed emotion-based model 


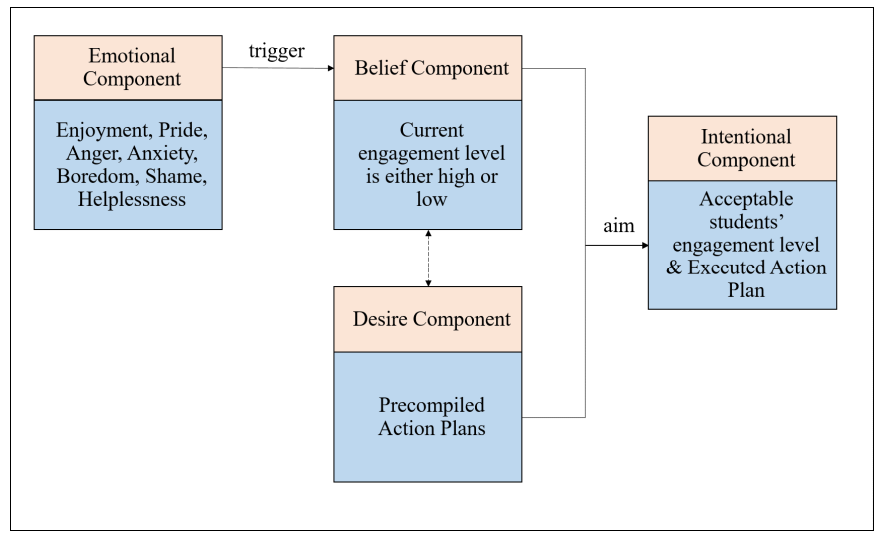

Fig. 3 Lecturer agent architecture

\section{RESULT AND DISCUSSIONS}

The following are the preliminary symbolic formulation for students' engagement level, lecturer' emotional state, and students' emotional state. If Student is St, Emotion is Em, Lecturer is Lc, Engagement level is EngagementLevel, Average is avr, then,

1) Talking out of turn, no attentiveness and playing video games are the indicators of student misbehaviours, $\mathrm{MisB}$, in a classroom.

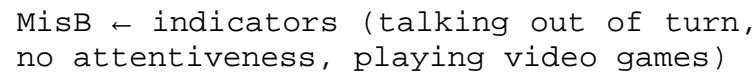

2) Having good class attendance, attentive and maintaining eye contact with lecturers are the indicators of highly motivated, Mtv, student.

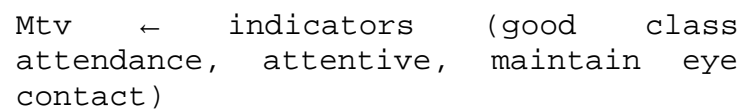

3) Asking question, taking part in discussion and assessment are the indicators of student participation, Ptc, in a classroom.

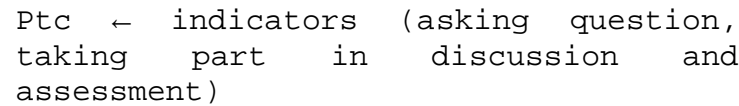

4) Engagement level is measured based on the average values of the three variables, MisB, Mtv, Ptc.

EngagementLevel $=\operatorname{avr}(\mathrm{MisB}, \mathrm{Mtv}, \mathrm{Ptc})$

5) Engagement level influences the emotional state of lecturer, $\operatorname{EM}(\mathrm{Lc})$.

$$
\text { EM }(L C) \leftarrow \text { EngagementLevel }
$$

6) Therefore, the lecturer takes an action plan to improve student engagement level.

$$
\text { Lc } \rightarrow \text { Take (ActionPlan) }
$$

7) The action plan taken by the lecturer influences emotional state of the student.

\section{$\mathrm{EM}(\mathrm{St}) \leftarrow$ ActionPlan}

The formulation will be embedded in a multi-agent architecture to create a simulation model. For example, the lecturer agent in the ABSS would be using the following algorithm to decide whether to maintain or update a proposed action plan. The following section shows the student engagement evaluation algorithm.

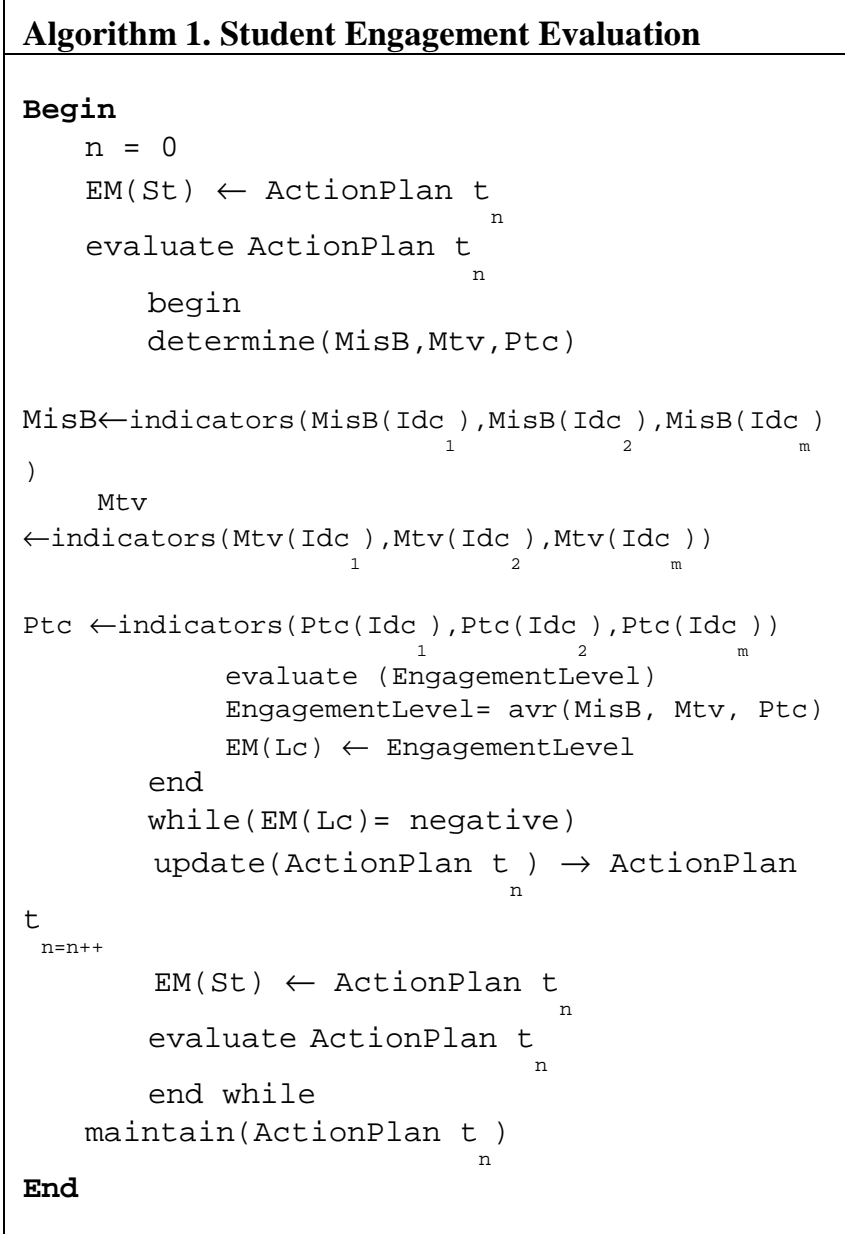

Conducting this study and analysing various environmental settings can help to explore several issues such as, what are the action plans that can help to improve students' engagement and which action plan(s) is/are the most effective and which is/are the least effective; what is the optimal complexity level of a plan to improve the engagement in shorter time; what is the average time to improve students' engagement if it is low; and what is/are the ideal action plan a lecturer can consider at time 0 (before having evaluated the engagement level); and many other issues.

\section{CONCLUSIONS}

Our scope of this research is to improve students' engagement in a classroom by emphasizing emotion as a factor to intensify the engagement and propose an action plan in an agent environment. Students' misbehavior, motivation, and participation are identified variables that 
reflect students' engagement level in a classroom. This subsequently affects the emotional state of a lecturer and the emotional states of students.

The impact of this research is the mitigation of poor students' engagement problem. It presents a social problem to many schools and universities and impacts negatively on the society. In our future work, we shall explore the possible action plans and build the proposed emotion-based model using logical and mathematical formulation.

\section{REFERENCES}

[1] Sagayadevan, Vathsala, and Senthu Jeyaraj. "The role of emotiona engagement in lecturer-student interaction and the impact on academic outcomes of student achievement and learning." Journal of the Scholarship of Teaching and Learning 12.3 (2012): 1-30.

[2] E. Skinner. et al. "Engagement and disaffection in the classroom: Part of a larger motivational dynamic?." Journal of Educational Psychology 100.4 (2008): 765.

[3] Ricard, Nathalie C., and Luc G. Pelletier. "Dropping out of high school: The role of parent and teacher self-determination support, reciprocal friendships and academic motivation." Contemporary Educational Psychology 44 (2016): 32-40.

[4] D.J. Shernoff. et al. "Student engagement as a function of environmental complexity in high school classrooms." Learning and Instruction 43 (2016): 52-60.

[5] Wubbels, T., Brekelmans, M., Mainhard, T., den Brok, P., and van Tartwijk, J. "Teacher-Student Relationships And Student Achievement." Handbook of Social Influences in School Contexts: Social Emotional, Motivation, and Cognitive Outcomes, (2016): 127.

[6] Macal, Charles M., and Michael J. North. "Agent-based modeling and simulation." Winter simulation conference, 2009.

[7] Bousquet, François, and Christophe Le Page. "Multi-agent simulations and ecosystem management: a review." Ecological modelling 176.3 (2004): 313-332.

[8] Fredricks, Jennifer A., Phyllis C. Blumenfeld, and Alison H. Paris. "School engagement: Potential of the concept, state of the evidence." Review of educational research 74.1 (2004): 59-109.

[9] Pekrun, R., Cusack, A., Murayama, K., Elliot, A. J., and Thomas, K. (2014). The power of anticipated feedback: Effects on students achievement goals and achievement emotions. Learning and Instruction, 29, 115-124Trowler, Vicki. "Student engagement literature review." The Higher Education Academy 11 (2010): 1-15.

[10] Trowler, Vicki. "Student engagement literature review." The Higher Education Academy 11 (2010): 1-15.

[11] Harper, Shaun R. "Institutional seriousness concerning Black male student engagement: Necessary conditions and collaborative partnerships." (2009).

[12] Kort, Barry, Rob Reilly, and Rosalind W. Picard. "An Affective Model of Interplay between Emotions and Learning: Reengineering Educational Pedagogy-Building a Learning Companion." icalt. Vol. 1. 2001.

[13] Pekrun, Reinhard. "The control-value theory of achievement emotions: Assumptions, corollaries, and implications for educational research and practice." Educational psychology review 18.4 (2006): 315-341.

[14] Goetz, Thomas. et al. "Students' emotions during homework: Structures, self-concept antecedents, and achievement outcomes." Learning and Individual Differences 22.2 (2012): 225234.

[15] Linnenbrink-Garcia, Lisa, and Reinhard Pekrun. "Students' emotions and academic engagement: Introduction to the special issue." Contemporary Educational Psychology 36.1 (2011): 1-3.

[16] Ahmed, Moamin, Mohd Sharifuddin Ahmad, and Mohd Zaliman M. Yusoff. "Modeling agent-based collaborative process." International Conference on Computational Collective Intelligence. Springer Berlin Heidelberg, 2010.

[17] A. K. Itaiwi. et al. "A framework for resolving task overload problems using intelligent software agents." Control System, Computing and Engineering (ICCSCE), 2011 IEEE International Conference on. IEEE, 2011.
[18] Ahmed, Moamin, Mohd Sharifuddin Ahmad, and Mohd Zaliman M. Yusoff. "A collaborative framework for multiagent systems." Asian Conference on Intelligent Information and Database Systems. Springer Berlin Heidelberg, 2010.

[19] Ahmed, Moamin, Mohd Sharifuddin Ahmad, and Mohd Zaliman M. Yusoff. "Mitigating human-human collaboration problems using software agents."KES International Symposium on Agent and MultiAgent Systems: Technologies and Applications. Springer Berlin Heidelberg, 2010.

[20] A.K. Itaiwi. et al. "A multi-agent framework for dynamic task assignment and delegation in task distribution." Computer \& Information Science (ICCIS), 2012 International Conference on. Vol. 1. IEEE, 2012.

[21] M.A. Mahmoud. et al. "A review of norms and normative multiagent systems." The Scientific World Journal 2014 (2014).

[22] M.A. Mahmoud. et al. "Obligation and Prohibition Norms Mining Algorithm for Normative Multi-agent Systems." KES-AMSTA. 2013.

[23] M.A. Mahmoud. et al. "Norms detection and assimilation in multiagent systems: a conceptual approach." Knowledge Technology. Springer Berlin Heidelberg, 2012. 226-233.

[24] M.A. Mahmoud. et al. "A norms mining approach to norms detection in multi-agent systems." Computer \& Information Science (ICCIS), 2012 International Conference on. Vol. 1. IEEE, 2012.

[25] Mahmoud, Moamin A., Mohd Sharifuddin Ahmad, and Mohd Zaliman M. Yusoff. "A Norm Assimilation Approach for Multi-agent Systems in Heterogeneous Communities." Asian Conference on Intelligent Information and Database Systems. Springer Berlin Heidelberg, 2016.

[26] Subramainan, Latha, Mohd Zaliman Mohd Yusoff, and Moamin A Mahmoud. "A classification of emotions study in software agent and robotics applications research." Agents, Multi-Agent Systems and Robotics (ISAMSR), 2015 International Symposium on. IEEE, 2015.

[27] Yusoff, M. Z., and B. du Boulay. "Integrating Domain-Independent Strategies into an Emotionally Sound Affective Framework." In proceeding, Agents that want and like: motivational and emotional roots of cognition and action: Symposium of AISB, University of Hertfordshire. 2005.

[28] Macal, Charles, and Michael North. "Introductory tutorial: Agentbased modeling and simulation." Proceedings of the 2014 Winter Simulation Conference. IEEE Press, 2014.

[29] Ahmed, Moamin, Mohd Sharifuddin Ahmad, and Mohd Zaliman M. Yusoff. "A collaborative framework for multiagent systems." Asian Conference on Intelligent Information and Database Systems. Springer Berlin Heidelberg, 2010.

[30] Ahmed, Moamin, Mohd Sharifuddin Ahmad, and Mohd Zaliman M. Yusoff. "Mitigating human-human collaboration problems using software agents."KES International Symposium on Agent and MultiAgent Systems: Technologies and Applications. Springer Berlin Heidelberg, 2010.

[31] A.K Itaiwi. et al. "A multi-agent framework for dynamic task assignment and delegation in task distribution." Computer \& Information Science (ICCIS), 2012 International Conference on. Vol. 1. IEEE, 2012.

[32] Davidsson, Paul. "Agent based social simulation: A computer science view."Journal of artificial societies and social simulation 5.1 (2002).

[33] Sun, Ron, and Isaac Naveh. "Simulating organizational decisionmaking using a cognitively realistic agent model." Journal of Artificial Societies and Social Simulation 7.3 (2004).

[34] Kr Kravari, Kalliopi, and Nick Bassiliades. "A survey of agent platforms."Journal of Artificial Societies and Social Simulation 18.1 (2015): 11

[35] A.C. Frenzel. et al. Antecedents and effects of teachers' emotional experiences: An integrated perspective and empirical test. Springer US, 2009.

[36] A.C. Frenzel. et al. "Teaching This Class Drives Me Nuts!-Examining the Person and Context Specificity of Teacher Emotions." PloS one 10.6 (2015): $\mathrm{e} 0129630$

[37] Borg, Mark G., Richard J. Riding, and Joseph M. Falzon. "Stress in teaching: A study of occupational stress and its determinants, job satisfaction and career commitment among primary schoolteachers."Educational Psychology 11.1 (1991): 59-75. 
[38] Goetz, Thomas. et al. "Between-and within-domain relations of students' academic emotions." Journal of Educational Psychology 99.4 (2007): 715.

[39] Gläser-Zikuda, Michaela, and Stefan Fuß. "Impact of teacher competencies on student emotions: A multi-method approach." International Journal of Educational Research 47.2 (2008): 136-147.
[40] Gibson, Angela M., Jinhao Wang, and John R. Slate. "Teachers Behaving Unprofessionally: Stories from Students." International Journal of Educational Leadership Preparation 4.1 (2009): n1.

[41] Krause, K. "Understanding and promoting student engagement in university learning communities." Paper presented as keynote address: Engaged, Inert or Otherwise Occupied (2005): 21-22. 